\title{
EXPERIMENTING WITH ORGANISATIONAL DEVELOPMENT IN BHUTAN: A TOOL FOR REFORM AND THE ACHIEVEMENT OF MULTI-LEVEL GOALS?
}

\author{
JANINE O'FLYNN $^{1 *}$ AND DEBORAH BLACKMAN ${ }^{2 \dagger}$ \\ ${ }^{1}$ The Australian National University, Australia \\ ${ }^{2}$ University of Canberra, Australia
}

\begin{abstract}
SUMMARY
In this article we present a unique study of how a nation, Bhutan, is using a specific change management approachorganisational development-as the lever for system-level change in pursuit of a complex, multi-level suite of goals to, ultimately, enhance Gross National Happiness (GNH). We argue that this represents one of the first attempts at using OD for wide-scale change, something hinted at decades ago, and flagged by recent work coming out of the United Nations Development Program and civil society organisations (CSOs). Conceptually, we point to a high level of fit between the Bhutanese development philosophy and OD, and argue there is great potential for using OD in the context. However, we raise a series of issues around the practical feasibility of this approach highlighting important points of tension which pose major challenges for the Bhutanese experiment. Copyright (C) 2009 John Wiley \& Sons, Ltd.
\end{abstract}

KEY WORDS - organisational development; civil service reform; Bhutan; Gross National Happiness

\section{INTRODUCTION}

Bhutan stands at an historic crossroads and is currently pursuing major political, social and institutional reform in its transition to democracy. A central part of this agenda has been a commitment to retooling and refocusing the civil service and a series of reforms has been enacted linked to the internationally popular goals of capacity building and good governance. In the Bhutanese case good governance is tied to four pillars - transparency, accountability, efficiency and professionalism - and has been explicitly linked to facilitating Gross National Happiness (GNH), the unique Bhutanese development philosophy (RGoB, 2005a). The role of the civil service is central: the public sector dominates in Bhutan and through change in the civil service the capacity to meet the twin challenges of democracy and development is being pursued.

As the United Nations has noted, 'the business of development is about change': in a developing country context this goes far beyond the notion of changing a single organisation towards a major reconfiguration of the system itself (UNDP, 2006, p. 6). In Bhutan much faith has been placed in a specific change management approach, OD and the government has committed to a comprehensive and ongoing programme of OD exercises aimed at linking together processes of civil service reform, capacity building and national development. OD in this context is being constructed as a means of effecting major change across multiple organisations, in pursuit of multi-level economic and social goals. This in itself goes far beyond the typical use of OD which, in the main, is a planned change approach used at the workgroup or organisational level. Actual attempts to use OD to lever system-level change is unheard of in the literature.

*Correspondence to: Dr J. O'Flynn, Crawford School of Economics and Government, JG Crawford Building (Building 13), The Australian National University, ACT 0200, Australia. E-mail: janine.oflynn@anu.edu.au

${ }^{\dagger}$ Associate Professor 
A thorough review of the literature indicates that there has been little attention paid to how governments, as opposed to specific public sector organisations, use discrete change management tools to achieve multi-level, system-wide goals. Evidence of such studies in a developing country context is even more elusive. Rather, both theoretical and empirical studies have been more focussed on how transferable Western management techniques are to non-Western and developing countries (Blunt and Jones, 1997; McCourt and Ramgutty-Wong, 2003; O'Donnell and Turner, 2005; Zupan and Kase, 2005; Ozturk and Swiss, 2008) and on the application of strategic human resource management and change concepts to public sector organisations (Tompkins, 2002). Such literatures provide very useful guidance on the opportunities and challenges of using Western-inspired management tools in development; however we still seem to be missing the connection between the adoption of such techniques and the complex set of multi-level goals which these tools are enacted in pursuit of. We find this lack of attention quite surprising given some of the bold claims permeating the development world, for example: 'the way governments manage their public servants can improve the performance of an entire national economy' (AlArkoubi and McCourt, 2004, p. 978).

The main aim of this article is to examine whether OD can be used to achieve multi-level goals in a developing country context. In addressing this overarching question we present a unique case of OD being used for planned social change, a potential application flagged more than 30 years ago by Friedlander and Brown (1974), and reinvigorated by ideas emanating from the United Nations Development Program (UNDP) and civil society organisations (CSOs). We pose four sub-questions which we address through the article: first, is OD an applicable tool for planned social change? second, how applicable is OD to the specific case of Bhutan? third, how is OD being used in Bhutan to enable the achievement of multi-level goals? and fourth, what are the challenges for OD in Bhutan? Our findings provide an important contribution to the literature on public sector reform in developing countries, in particular through addressing how connections might be made between management tools, civil service reform and national development.

The article is arranged in to three main sections. The first provides readers with an overview of the Bhutanese reform agenda, an introduction to the development concept of GNH and key development goals. The second section provides a discussion of OD as a change management tool. In the third section we set out the case of OD in Bhutan, providing readers with an overview of the OD strategy and its implementation in Bhutan, highlighting several key tensions which have emerged. These findings underpin our claim that, whilst offering considerable potential in this setting, the OD approach adopted may undermine this potential in practice.

\section{THE BHUTANESE STORY OF MODERNISATION AND REFORM: SETTING MULTI-LEVEL GOALS}

\section{Modernising Bhutan}

Bhutan is a small landlocked country geographically located between the rapidly developing nations of India and China. Officially the population is 672,000 , the majority located in rural areas. ${ }^{1}$ Life in Bhutan is rooted in Buddhism with religion and politics intertwined; traditional educational and monastic institutions have had a long and important influence on the state, its ethics and laws (Thinley, 1998; Mathou, 2000). This reflects, in part, the fact that Bhutan was ruled by a diarchy of lay and religious leaders until the creation of a monarchy in the early 1900s (Bray, 1993).

Modernisation began in the 1960s under the third King who reformed the legal framework and instituted a National Assembly. The fourth King accelerated reform, drafting a constitution, shifting powers to the Prime Minister, and introducing democratic elections, the first of which took place in March 2008. The fifth King, crowned in 2008, continues the modernisation agenda. ${ }^{2}$ Modernisation has been guided by five-year plans since the 1960s, with significant improvements recorded: between 1984 and 1998 life expectancy at birth rose from 47.4 to 66 years, adult literacy from 23 to 54 per cent and real GDP by almost two-thirds, shifting Bhutan into the medium

\footnotetext{
${ }^{1}$ Data from the first official census carried out in 2005 and reported at: www.bhutancensus.gov.bt accessed 10 October 2007.

${ }^{2}$ Although he essentially took power in 2006 following the abdication of the fourth King, the formal coronation of the fifth King did not occur until November 2008. Much has been made of the fact that the fifth King, Jigme Kesar Namgyal, was educated at Oxford University.
} 
development category (Planning Commission, 2000). This relatively rapid development has been attributed to strong coordination, clear direction, farsighted leaders, a rich endowment of natural resources, a well-developed administrative machine, the commitment of foreign donors and the Bhutanese culture (Ura, 2004). It has been argued, however, that Bhutan's development could have been more rapid had it not been so deeply committed to protecting the environment and its national culture (Thinley, 1998).

\section{Bhutanese development philosophy and goals: gross national happiness}

Bhutan has blended tradition and modernity to develop a unique approach built on consensus, compassion, respect for life and nature, compromise and individual development; from this a distinctive model of governance and institution-building has emerged (Mathou, 2000). The Bhutanese reject Gross Domestic Product (GDP) as the measure of development in favour of GNH, a concept introduced by the fourth King in the late 1980s. This has provided an important symbol for the Bhutanese who have followed 'a multi-dimensional approach to development ... aimed at spiritual and material balance and harmony' (Thinley, 1998, p. 22).

GNH is centred on a desire to improve and maximise happiness rather than economic growth (Planning Commission, 1999). This recognises the multiple needs of individuals and, whilst accepting that material wellbeing is important, GNH is a much broader development philosophy reflecting the spiritual roots of Bhutan. It has been argued that GNH captures the Buddhist emphasis on emotional and spiritual well-being where the ultimate purpose of life is inner happiness (Priesner, 1999; Tideman, 2001; Hewavitharana, 2004; Lokamitra, 2004; Tashi, 2004). This reflects the idea that 'the overarching goal of every aspect of life, including economics, is not seen as the multiplication of material wants ... but in the purification of the human character' (Priesner, 1999, pp. 36-37). Similarly, Ura (2004, p. 2) argued that GNH was based on the Buddhist ideal that happiness stems not from material goods but from 'unquantifiable spiritual and emotional well-being'. The connection between Buddhism and development has been clearly articulated by Bhutanese leaders:

[GNH] best captured our distinct perception of the main purpose of development, rooted in our philosophical and political thought... We asked ourselves the basic question of how to maintain the balance between materialism and spiritualism, in the course of getting the immense benefits of science and technology. The likelihood of loss of spiritualism, tranquillity, and [GNH] with the advance of modernisation became apparent to us (Thinley, 1998, p. 15).

In a 2005 speech, the Minister for Home and Cultural Affairs ${ }^{3}$ noted that Buddhism had long provided the basis for politics, policy and its social contract which explained why the Bhutanese have 'a predisposition towards a more holistic, unconventional approach to development which recognises happiness as the primary and perhaps, only purpose of development' (Thinley, 2005, p. 3). Some have argued GNH is the Bhutanese contribution to Buddhist economics, and GNH is the Buddhist version of GNP (Tideman, 2001). ${ }^{4}$ Others assert the Bhutanese are creating a new type of state where happiness is the central policy concern, the arbiter of policies, the core of institutions and the key evaluation criterion (Ura, 2004; Thinley, 2005). This is a conscious effort to by-pass industrialisation in pursuit of a post-modern sustainable state (Ura, 2004). Regardless of the scope of their contribution, it is clear that the Bhutanese are pursuing, 'a genuinely non-western development approach, which considers non-economic goals more important than economic ones' (Priesner, 1999, p. 40).

GNH rests on four pillars: economic self-reliance; conservation of the environment; preservation and promotion of culture ${ }^{5}$ and good governance (Thinley, 1998, 2005). These have then been translated into five specific

\footnotetext{
${ }^{3}$ Jigme Thinley, the first elected Prime Minister of Bhutan whose party won 45 of the 47 seats in the National Assembly in 2008.

${ }^{4}$ Reviewing the literature on Buddhist economics provides a means of understanding the Bhutanese rejection of GDP. Schumacher (1966) discusses, for example, the problems for Buddhists in measuring the standard of living via the amount of annual consumption and the assumption that higher consumption makes people better off. He notes that 'Buddhist economics would consider this approach excessively irrational: since consumption is merely a means to human well-being, the aim should be to obtain the maximum well-being with the minimum of consumption' (1966 n.p.).

${ }^{5}$ Further, the GNH state would celebrate and protect the indigenous culture, something often identified as a barrier to economic development, allowing development to be centred on spiritual values and culture (see Tideman, 2001).
} 
development objectives: human development which enables people to fulfil their potential; protection of the unique culture and heritage of Bhutan; balanced and equitable development to ensure harmony, stability and unity; environmental conservation based on principles of sustainability; and governance based on developing institutions, human resources and governance systems to enhance self-sufficiency, build capacity and enable participation (Planning Commission, 1999, part 2, pp. 12-14). Links between Buddhism and GNH can also been seen here, for example the focus on environmental protection and sustainability reflects the Buddhist commitment to harmony (Ura, 2004; see also Schumacher, 1966 on Buddhist economics). In 2008, a GNH Commission was created to enable the integration of the GNH philosophy into Bhutanese plans and policies and the development of GNH measures and indicators including the Bhutan Development Index (Kuensel, 2008).

The most explicit articulation of the multi-level goals being pursued as part of GNH is contained in Bhutan 2020: A Vision for Peace, Prosperity and Happiness. Here a normative architecture is set out which incorporates a 'hierarchy of goals, objectives and principles that should guide the Kingdom's development over the next two decades' (Planning Commission, 1999 part 2, p. 5). In Figure 1, we see the unifying priority, several guiding principles and five main objectives which together provide the multi-level goal framework for Bhutan.

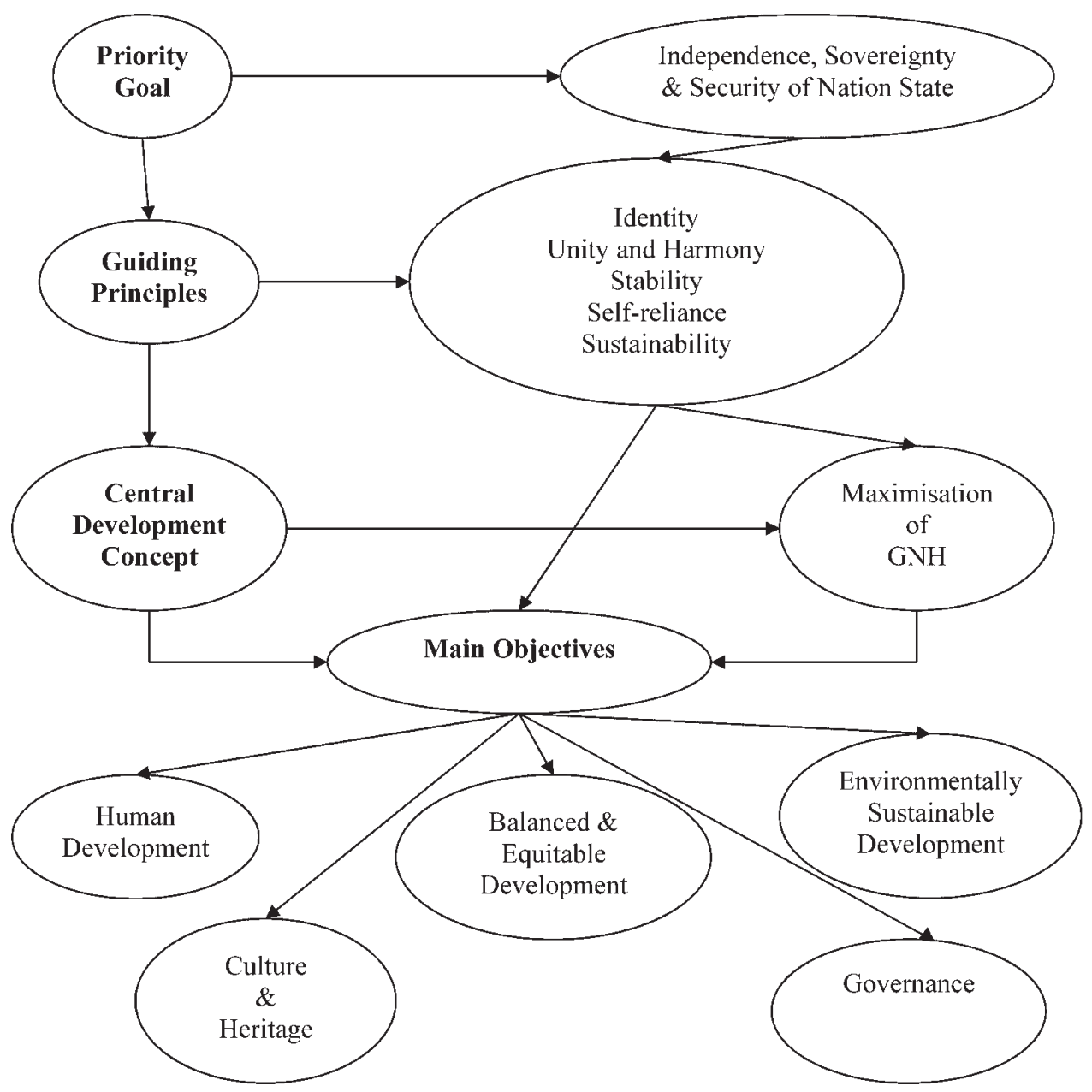

Figure 1. The normative architecture for change and development in Bhutan. Adapted from Planning Commission (1999, part II, p. 15). 


\section{Bhutanese development: civil service reform and governance goals}

The modernisation agenda entails considerable reform for the civil service. Over the last few decades considerable change has taken place to reduce the reliance on foreign professionals, train local staff, improve coordination and ensure clearer lines of responsibility (Mathou, 2000). However significant change is on the horizon, particularly under the 'governance pillar' of GNH and specific objectives set out in Bhutan 2020 which point to capacity building, civil service reform, institutional redesign and human resource development as targets for reform. In Bhutan 2020, seven goals explicitly connect civil service change with national development:

1. Government should enable not drive development.

2. Responsibility for development should be decentralised and shared.

3. Management capacities need to be strengthened to direct development in an increasingly complex environment.

4. Planning and management instruments need to be developed to ensure adaptability and responsiveness.

5. A managerial focus requires professionalisation, restructuring and reconfiguration of the civil service.

6. Investment in data collection and management systems is required for better decision making and evaluation.

7. Management development must incorporate a distinctly Bhutanese approach.

Civil service reform has been captured under the banner of good governance which, as in many developing countries, has become an important part of reform. The first exercise to enhance governance was carried out in 1999 and three key themes were identified-efficiency, transparency and accountability. In a 2005 review, 'Good Governance Plus' incorporated professionalism as well (RGoB, 2005a). Good Governance Plus is seen as central to $\mathrm{GNH}$, and in the report a vision of a 'new public service' was set out including detailed goals for improving the role and character of the civil service, rightsizing and improving service delivery (RGoB, 2005a, p. 28). This 'new' public service would be achieved via two means. Firstly, a new Civil Service Act to govern the civil service. And second, and more importantly, the introduction of a Position Classification System (PCS) to explicitly connect individual civil servants to organisational goals and functions. This would require a major reform programme incorporating changes to performance management, recruitment, selection and promotion, human resource development and remuneration and benefits (RGoB, 2005b). At the launch of the PCS, the Prime Minister argued it would provide the basis for a dynamic, responsive, adaptive, professional, service-oriented civil service which would ensure good governance and the realisation of GNH (RGoB, 2005b). Further, it would improve civil service capacity to ensure that Bhutan developed and maintained a small, compact and efficient civil service (RGoB, 2005b).

\section{ORGANISATIONAL DEVELOPMENT: A TOOL FOR ACHIEVING MULTI-LEVEL GOALS?}

Bhutan is clearly undertaking a considerable change in its political and bureaucratic architecture and a critical part of that has been the identification of a series of interconnected goals which, in part, will be pursued via major civil service reform. Whilst the change management literature offers a smorgasbord of models from which to choose (Ancona et al., 1999), in Bhutan, OD has emerged as the favoured approach. OD has its roots in the work of Lewin and the Human Relations School. At the core of Lewin's approach were ideals of allowing people active involvement in organisations and society in order to solve social conflict, and this lead him to advocate democratic values and institutions (Burnes, 2004). Whilst Lewin has famously been linked to organisational-level change he was most interested in societal change and, over time, he developed a complex change management system (Burnes, 2004). The Human Relations School drew heavily on Lewin's approach and came to espouse 'shared values, equality, power sharing, consensus and participative decision-making' as ideals (Bass and Steidlmeier, 1999, pp. 192-193). It has been argued that OD represents the best example of the Human Relations ideal of grass roots democracy (Bass and Steidlmeier, 1999).

Broadly defined as 'a set of behavioural science theories, values, strategies and techniques aimed at the planned change of organisation work settings' (Porras and Silvers, 1991, p. 54), OD aims to improve capacity for change, problem solving abilities, adaptability, effectiveness and quality of work life (Friedlander and Brown, 1974; Porras and Silvers, 1991; Ritson and O'Neill, 2006; Waddell et al., 2007). Values, largely drawn from Human Relations, have been central to OD which has been variously described as a participatory approach reliant on 'open discussion 
and individualistic, humanistic values' (James, 2004, p. 314), and as a value-based applied science with transcendental roots (Golembiewski, 2004). A series of writers have pointed to core OD values including human development, openness, fairness and collaboration (Friedlander and Brown, 1974; Hage and Finsterbusch, 1989; Burke, 1997; Waddell et al., 2007). OD has been described as inherently rational, because it assumes truth can be found, that change can be planned and managed and that behavioural modification is desirable; more recently this has been termed 'Classical OD' (Marshak and Grant, 2008). ${ }^{6}$

OD in practice is about facilitating planned change and interventions are usually classified along two dimensions: the target level of change - individual, group or organisation and the nature of change - task or people-oriented (Lau and Ngo, 2001). Practitioners draw on a range of techniques to enact change such as surveys, quality of work life programmes, human resource development, action research and skills training (Rao and Vijayalakshmi, 2000; Lau and Ngo, 2001). Whilst tools and approaches differ, three key elements of the traditional approach have been distilled: OD is systemic and holistic; OD is people-centred; and OD is participatory (James, 2004, p. 315).

OD tends to be used in two distinct ways: either as a micro-level recalibration tool, or in a more transformative way to address major organisation-environment mismatches (Porras and Silvers, 1991). In practice most interventions tend to be micro, but on rare occasions they have been used to attempt extensive organisational change (Hage and Finsterbusch, 1989). Evidence that OD has been used at a macro-level, for example across a group of organisations to address broader social issues is unheard of in practice, although the potential for this has been identified in the literature. Friedlander and Brown (1974, p. 335) argued more than 30 years ago that, "some of the potential richness and diversity of OD [is] represented in the application to wider planned social change activities... . Porras and Silvers (1991) agreed, arguing OD could potentially be used to address multi-level issues. More recently the UNDP made a case for integrating organisation-level change literature with broader development literature to enable a more sophisticated capacity development approach focussed on organisation, social, economic, political and cultural change (UNDP, 2006). These potentially broader applications of OD which would reflect Lewin's interest in social change have, in practice, been largely unexplored.

The positive picture of OD has been tarnished somewhat by a range of critiques. Some have argued it is broad and meaningless (Hage and Finsterbusch, 1989), others that it relies too heavily on practitioner-reported success for evidence (Friedlander and Brown, 1974). Pettigrew argued OD was too focussed on change episodes rather than actual change and that it relied on an 'uncomfortable mixture' of values from humanistic psychology: OD, he argued, is 'aprocessual, ahistorical and acontextual' (Pettigrew 1985, cited in Pettigrew et al., 1988, p. 307). Several writers have also questioned how useful OD is in the public sector (Davis, 1979), despite evidence that there are similar success rates to private sector interventions (Golembiewski et al., 1981; Robertson and Seneviratne, 1995 cited in Rainey, 2003). ${ }^{7}$ From this wide-ranging critique, one of the central tensions was identified by Friedlander and Brown (1974, p. 335) who argued that the field was 'faced with decision about the balance it can and will strike between changing institutions to increase human development and changing people to promote institutional development. The two goals are rarely consistent with each other'. For us, this emerges as an interesting tension in the Bhutanese case where OD is being used to pursue multi-level goals.

One of the most prominent issues in the literature, and an important one in the context of this article, is the application of OD in non-Western settings. This fits into a broader debate about the influence of culture on management theories and techniques (see Hofstede, 1993), the relative ethnocentric nature of management and the notion in development settings that 'West is best' (Blunt and Jones, 1997). The question of whether particular theories and techniques 'fit' with culture thus becomes an important one. A review of the literature shows that OD has been used extensively in non-Western settings, and importantly in many developing countries. Debate over the appropriateness and success of this practice has, however, been ongoing. On the one hand, is an assertion that there

\footnotetext{
${ }^{6}$ Marshak and Grant (2008) have argued that new approaches built around appreciative enquiry have developed which underpin a postmodern 'New OD' concerned less with human and technical change, and more with transformational change through negotiating new realities, shifting mindsets and consciousness.

${ }^{7}$ It should be noted however that one of the common critiques of OD research is that it is reported by those involved in interventions and, therefore, it is more likely that successful interventions are reported (see for example Friedlander and Brown, 1974).
} 
will be inevitable tension between core OD values reflecting its Western origins (for example democracy and autonomy) and the values and norms of countries where, for example conformity and collectivism are important (Blunt and Jones, 1997). Such claims essentially rule out OD in non-Western countries. Supporters of OD, however, claim this position is based on cultural caricatures, outdated and narrow perspectives of OD and a failure to consider the diversity and dynamism of culture (James, 2004). Importantly, it has been argued that these critics fail to distinguish between OD per se and poor implementation of OD (James, 2004). On the other hand, there are several writers who argue OD can overcome cultural issues by drawing on a range of techniques and adapting interventions to suit the setting (Golembiewski and Luo, 1994; Ali, 1996). For example interactive interventions may be unsuitable in settings where hierarchy and status overwhelm 'authentic' relationships (Golembiewski and Luo, 1994); instead more directive approaches where 'organisational democracy is dictated from the top' might be used to ensure successful implementation (Ozturk and Swiss, 2008, p. 147; see also Rao and Vijayalakshmi, 2000 for a discussion on India). Thus, there is a strong argument that tailoring the intervention to the environment can overcome cultural barriers; the implication being that OD practitioners must pay attention to issues of culture in order to improve success rates, and also to overcome their own ethnocentric tendencies. As James (2004, p. 320) has argued: 'It is more often the OD techniques, images and language used by OD consultants that are foreign, not the values and principles underlying them'.

Adding to the richness of the OD-culture debate has been the discovery of OD in the aid world. This is especially relevant in the case of Bhutan where SNV, the Netherlands Development Agency, is sponsoring the OD exercise. ${ }^{8}$ Non-government organisations (NGOs)/CSOs have been especially attracted to the participatory philosophy and the focus on people which is part of OD and it is increasingly seen as a capacity building tool: hence, it is now a 'main priority' for many NGOs in their relationships with partners (James, 2004, p. 316). Recently, McAlpine (2007, p. 112) promoted OD as a tool for CSOs to 'align their core purpose and operating practices such that they could both inspire and implement significant and tangible change towards social justice'. OD would allow CSOs to 'work with a particular ethos and posture' and enable them to become 'mediators of social and economic change'. Reporting on CSOs in East Africa, McAlpine argued:

As these organisations become more aligned with the values and practices they are trying to propagate in communities, a more cohesive and dynamic vision of wider development within the region is catalysed... as the cultures of these organisations evolve and are strengthened by new systems, practices and behaviours, they become exemplars for ways of living which are grounded upon a will for social justice and a commitment to combat inequality, fear and poverty (McAlpine, 2007, p. 112).

$\mathrm{OD}$, it appears, is starting to be seen as a tool for major, systemic change not just organisational, work group or individual change. If we can link together the potential application of OD to broader social issues (Friedlander and Brown, 1974; Porras and Silvers, 1991), the increasing interest from aid agencies and NGOs/CSOs, and suggestions for integration from the UNDP then this, we argue, sets the scene for the novel experiment underway in Bhutan. Attempts to use OD to achieve multi-level goals represent an innovative and, potentially ground-breaking experiment which has the potential to address one of the major tensions in the OD world-how to balance individual and institutional development (Friedlander and Brown, 1974).

\section{EXPERIMENTING WITH ORGANISATIONAL DEVELOPMENT IN BHUTAN: POSSIBILITIES AND EMERGING TENSIONS}

In the next section we set out the Bhutanese OD experiment in order to identify the potential for its use in this setting, along with some emerging tensions. We draw on official documents, media reports and observation to present a preliminary analysis of the OD experiment.

\footnotetext{
${ }^{8} \mathrm{SNV}$ operates in more than 30 countries and its core interests are in reducing poverty and improving governance, with a special emphasis on empowerment (SNV, 2007). It has had bilateral relations with Bhutan since 1988. 


\section{$O D$ in Bhutan: strategy and implementation}

To enact the programme of change which will facilitate the achievement of its multi-level goals, the Bhutanese government has identified OD as the tool of choice. The OD strategy was officially launched in April 2007 at an Executive Seminar for all secretaries and directors in a turbulent political environment - the constitution was about to be adopted, elections were being planned and senior bureaucrats had started to drift from the civil service to newly forming political parties. In the strategy paper, it was argued that OD was introduced to 'strengthen the Civil Service for its important role in Bhutan's constitutional democracy and good governance in pursuit of [GNH]. OD is an essential exercise to further strengthen the reforms initiated... [including] Decentralisation, Position Classification System... and the Civil Service Act' (RGoB, 2007, p. 2). The Royal Civil Service Commission (RCSC) explained OD would provide the opportunity to address organisational and institutional issues and provide a focus on service delivery, restructuring and resizing. ${ }^{9}$ OD was identified as the tool for 'defining the right size of the Civil Service' (RGoB, 2007, p. 2). OD exercises would provide a means for government organisations to clarify their mandates and roles, and to ensure they were working in a coordinated way in pursuit of national goals (RCSC, 2007). In addition to making them more efficient and effective, OD would allow agencies to assess their relevance in an era of major political change (Dorji and Schreven, 2007). The key objectives of the programme were: the wellbeing of the people; building a strong basis for democracy; developing a high performing civil service; increasing efficiency and professionalism; delivering high quality services; setting high standards and capacity strengthening (RGoB, 2007).

Analysis of official documents indicates OD has been embedded in several policies underpinning the reform agenda. OD appears in the PCS where it is described as a monitoring and evaluation tools which can 'help to assess the overall health of the Civil Service' (RCSC, 2006, p. 64). OD also features in the Bhutan Civil Service Rules and Regulations where it is mandated that every 'Agency... undertake OD exercises regularly to enhance both organisation and individual performance', (RGoB, 2006, p. 2). In the Good Governance Plus report (RGoB, 2005a), OD was explicitly linked to the rightsizing agenda; outcomes of OD exercises are expected to form the basis for all decisions related to restructuring, staffing and capacity building.

The implementation programme for the OD strategy was the responsibility of the RCSC and two key governance bodies were created to assist in this. Firstly, a National OD Steering Committee which was to provide strategic guidance and support during the implementation of the OD exercises. Secondly, an OD Taskforce was created to design and implement the exercises under guidance from the Steering Committee. Implementation of OD began at the official launch in April 2007 where the timetable for completion was announced. In the first phase (AprilJune 2007) local focus people (i.e. those that would actually carry out the OD exercises) would be trained and seven pilot studies would be undertaken. In phase two (July-October 2007), all remaining exercises would be completed. Given this already optimistic timeframe, pressure was increased when it was announced that all exercises were to be completed by mid-September to ensure results were fed into the 10th five-year plan. (see footnote 9).

\section{The potential for $O D$ in Bhutan}

Discussions in previous sections highlight the transformational reform agenda underway in Bhutan where it appears there is much potential for using OD to achieve multi-level goals as was suggested by Friedlander and Brown (1974). This experiment brings us closer to Lewin's approach to change management which has inspired OD; however the evidence of OD being used in this way outside of Bhutan is scant. The potential for OD to work in this context comes from the overlap of core ideals. OD draws heavily on the ideals espoused by Lewin such as shared values and consensus (Bass and Steidlmeier, 1999) and, in the classical approach which has been adopted in Bhutan, it embodies values such as human development, well-being, democracy, effectiveness and developing the capacity to adapt and change. Such values are woven into the reform story of Bhutan and are reflected in the development philosophy of GNH, itself built around harmonious and humanistic ideals. The notions of OD as systemic, holistic and people-centred (James, 2004) also meld well with the scale, scope, vision and philosophy of

${ }^{9}$ www.rcsc.gov.bt, 22 August 2007. 
change in Bhutan. The issue of fit has been discussed in the literature and there are varying views on whether the level of fit between OD and national values is, or should be a barrier to the use of OD in non-Western setting (Jaeger, 1986; Blunt and Jones, 1997; James, 2004). And, whilst we have noted this debate, perhaps the more problematic issue has been the implementation of OD, rather than OD per se (James, 2004).

\section{Emerging tensions in the implementation of $O D$}

In the Bhutanese experiment one of the greatest challenges will be trying to use OD across multiple levelsindividual, workgroup, organisation, society. Whilst we can point to great potential here, our preliminary analysis points to a series of tensions emerging in the initial implementation phase. These, we argue, go to the key point made by James (2004), poor implementation undermines OD, rather than any clash of values.

One of the first tensions to emerge was around the 'true' purpose of the OD program - these concerns were expressed repeatedly at the Executive Seminar to launch OD. ${ }^{10}$ Initial responses indicated that the most senior civil servants believed OD was about reducing the size of the civil service, not enacting transformative change. Considerable scepticism about the timing of the programme was expressed with one Secretary suggesting it would be more appropriate to delay implementation until after the 2008 elections when the government would set new goals. Several participants raised questions about the authenticity of OD and how much control agencies would have in the process: one asked what would happen if following the OD exercises, agencies could identify a need for more staff? Interestingly this occurred in the pilot phase with agencies identifying a need for a 30 per cent increase in staff and this was followed soon after by the announcement of a zero growth strategy by the RCSC, effectively overriding agency requests (Kuensel, 2008). This highlighted an important tension in the Bhutanese experiment: what happens when the needs of agencies conflict with those of the central bureaucracy or, indeed, with other agencies? With the Bhutanese presenting a unique natural experiment of using OD to engineer system-wide change and achieve multi-level goals, such conflicts present fertile ground for future research. This also raises the possibility that OD was being used to implement a specific, pre-determined strategy: reducing, or at least, containing the size of government; a practice which 'violate[s] the values associated with OD', and indicates that OD has 'lost its way' (Burke, 1997, p. 7).

Another interpretation may be that OD is being used as an audit and evaluation tool rather than an approach to managing change. In part this may be driven by the donor agency's interpretation of OD: 'OD refers to an organisation's efforts to regularly assess its capacities so that it can take the right decisions and measures to continually improve performance and service delivery' (Dorji and Schreven, 2007, p. 3). This audit, as opposed to change, approach to OD was also evident in the discussion of initial OD exercises in a paper co-authored by one of the SNV officers (Dorji and Schreven, 2007). This problem may be exacerbated by the requirement that OD takes place on a regular basis - imposed OD can be problematic and may, in the end, be counterproductive (although there are supporters of directive OD such as Rao and Vijayalakshmi, 2000; Ozturk and Swiss, 2008).

Using OD for audit shifts it considerably from its traditional humanistic roots and we believe it creates an impediment to Bhutanese civil servants and government organisations contributing to the reform and development goals. Instead of getting a societal-level focus, an audit approach may instead lead to agencies looking inward rather than outward as they compete for a limited set of resources. Our preliminary analysis of the implementation phase suggests that the Bhutanese are drifting towards using OD for audit rather than change.

Time pressure also emerged as a critical tension in the implementation of OD. Whilst the initial suggestion of a year may have been optimistic, when the RCSC announced it was truncating the timeframe for agencies to undertake their first OD exercise this pointed to problems. On the one hand, this may have fit with the timetable for feeding into the 10th 5-year plan and the transition to democracy, it contradicted important principles of OD. There is a strong emphasis in the OD literature on allowing time to get buy-in from staff at all levels of the organisation to generate ideas and commitment to change. If participants do not believe that they have had adequate time to

\footnotetext{
${ }^{10}$ OD Executive Seminar, 16 April 2007, Thimphu, Bhutan. This involved around 100 of the most senior civil servants in Bhutan. The authors presented some academic material at the seminar and observed proceedings.
} 
undertake their OD this may have long-term implications for commitment to both the ongoing OD program, and the broader change programme which it is feeding in to.

A further tension centres on the role of donor agencies in the reform agenda, especially as advocates and supporters of OD. As James (2004) noted, aid agencies often see OD as central to their relationships with partners, and in the Bhutanese case OD has been championed by SNV. Of course, this does not imply that it is automatically problematic, but it does raise questions about 'technique peddling', especially as OD is emerging as a tool for audit and evaluation, not change. McAlpine (2007, p. 113) pointed to problems associated with donors imposing OD as part of their funding agreements: 'there is a fundamental tension between an OD practice that is underpinned by integrity - that has been sought out by [those] who have identified their own need and desire to change — and the use of OD by... donors agencies that impose it...'. This is a problem acknowledged in the broader development literature where there has been considerable discussion of the buy-in and ownership issues which emerge during implementation when aid agencies push particular means of reform (see O'Donnell and Turner, 2005 for a good example).

Finally, there is an issue of tension between the strategic goals of OD as set out in the official approach, and the realities of bottom-up OD change. Whilst conceptually it is possible to make the case that the Bhutanese could use OD to pursue big picture strategic goals, the work of Sminia and Nistelrooij (2006) identifies the tensions between strategic change and grass roots change as problematic in practice even within organisations. The authors found that strategies which call upon OD as the change model but do not see it through create scepticism, diminished trust and reduce confidence. There is real potential for this to emerge as an issue in Bhutan given the complex mixture of goals, the change taking place across the country and the way in which it appears OD will be used. Finding a balance between national-level strategy reform and change, micro-level behavioural change and all that goes between poses a significant challenge for the Bhutanese.

\section{CONCLUSIONS}

In this article, we have provided a preliminary analysis of the use of OD to pursue multi-level goals using the specific case of Bhutan. Over time and as the regular waves of OD exercises are undertaken more in-depth research will be possible. At this stage we offer readers a report on the experiment in its initial stages, setting out the multilevel goals of development, the OD strategy and implementation, and the tensions emerging in practice.

As we have noted, the use of OD to try and achieve multi-level, complex economic and social goals is something that has been alluded to in the OD literature but the way in which it is playing out in Bhutan is, we believe, unprecedented. Here, we have provided a rare case of a nation tying an organisational change model to a complex suite of public sector and national reform and, in doing so, linking micro-, meso- and macro-level goals. This provided a rare example of the conceptual potential of OD as a tool for broader social change in the Lewinian sense. Conceptually we found there were grounds for using OD in this way, and this has been bolstered by the current attention to using organisational change models to address broader social and economic goals (for example UNDP, 2006). However, in examining the case of Bhutan we have raised issues around the practical feasibility of this approach which, whilst conceptually sound, has encountered a range of tensions barriers in situ. Not least of which has been the challenges of balancing human and institutional needs. In identifying these tensions we provide a link between organisational level change literature and the broader development literature, a gap recently identified by the UNDP (2006).

Our study also has practical implications which will be of interest to readers. First, the case of Bhutan provides evidence that nations are experimenting with linking organisational change models to multi-level goals, not just organisational change. This may provide some inspiration for governments who are considering how they might make connections between reform at the micro, meso and macro level. Some caution, however, is warranted because the Bhutanese have placed great faith in a single tool to enact this complex suite of changes. It has, in effect, become the 'one-best-way' to go about planned change, regardless of the specific needs of each of the constituent public sector organisations which make up the Bhutanese civil service. 
Secondly, there appears to be great potential for the use of OD in Bhutan given the synergies of values underpinning reform and the long-held values of classical OD; thus we argue OD appears to be applicable in the Bhutanese case, despite a broader debate in the literature about the problems of the cultural-boundedness of specific techniques. Philosophically, the Bhutanese have attempted to balance the tensions between human and institutional development using OD — the ultimate challenge as set out by Friedlander and Brown (1974). In practice, however it appears that the implementation of OD is being used to undertake audit processes, indicating that it is institutional reform and development which has taken precedence over human development. In the context of its unique development philosophy and the official discourse on linking individual and national development, we find the implementation of OD to be problematic. Not only does this approach potentially transgress the values of OD, it has the potential to undermine the longer-term, multi-level goals which Bhutan is seeking to achieve. This creates an issue of the rhetoric and reality of OD. Classically, OD is a tool used to increase capacity for change, problemsolving and adaptability, whilst also improving the quality of work life of employees; however, there is sufficient evidence even at this preliminary stage to make the argument that OD is being used as an audit tool.

Third, our preliminary analysis suggests that the initial implementation phase is raising a series of serious challenges or tensions for the Bhutanese which, we argue may undermine this experiment in using OD to enact social and political change of the order not yet seen in practice. Finding some balance between human and institutional development needs, and enacting change to achieve this complex set of goals poses a mighty challenge indeed.

\section{ACKNOWLEDGEMENTS}

The authors acknolwedge the helpful advice and suggestions of reviewers.

\section{REFERENCES}

Al-Arkoubi K, McCourt W. 2004. The politics of HRM: waiting for Godot in the Moroccan civil service. International Journal of Human Resource Management 15(6): 978-995.

Ali AJ. 1996. Organizational development in the Arab world. The Journal of Management Development 15(5): 4-21.

Ancona D, Kochan T, Scully M, Van Maanen J, Westney DE, Kolb DM, Dutton JE, Ashford SJ. 1999. Organizational Behavior \& Processes. South-Western, Massachusetts Institute of Technology: Boston.

Bass BM, Steidlmeier P. 1999. Ethics, character, and authentic transformational leadership behavior. Leadership Quarterly 10(2): 181-217.

Blunt P, Jones ML. 1997. Exploring the limits of Western leadership theory in East Asia and Africa. Personnel Review 26(1/2): 6-23.

Bray J. 1993. Bhutan: the dilemmas of a small state. The World Today November: 213-216.

Burke WW. 1997. The new agenda for organization development. Organization Dynamics 25(1): 7-21.

Burnes B. 2004. Kurt Lewin and the planned approach to change: a re-appraisal. Journal of Management Studies 41(6): 977-1002.

Davis TRV. 1979. OD in the public sector: intervening in ambiguous performance environments. Group \& Organization Studies 4(3): $352-365$.

Dorji BP, Schreven AM. 2007. Gross National Happiness and Good Governance: Civil Service Reform towards achieving Gross National Happiness. Paper presented at 3rd International Conference on Gross National Happiness, 22-28 November, Bangkok.

Friedlander F, Brown LD. 1974. Organization development. Annual Review of Psychology 25: 313-341.

Golembiewski RT. 2004. Twenty questions for our future: challenges facing OD and ODers, or whatever it is labeled. Organization Development Journal 22(2): 6-20.

Golembiewski RT, Luo H. 1994. OD applications in development settings: an addendum about success rates. The International Journal of Organizational Analysis 2(3): 295-308.

Golembiewski RT, Proehl CW, Sink D. 1981. Success of OD applications in the public sector: totting up the score for a decade, more or less. Public Administration Review 41(6): 679-682.

Hage J, Finsterbusch K. 1989. Three strategies of organizational change: organizational development, organizational theory and organizational design. International Review of Administrative Sciences 55(1): 29-57.

Hewavitharana B. 2004. Framework for Operationalizing the Buddhist Concept of Gross National Happiness In Gross National Happiness and Development: Proceedings of the First International Conference on Operationalizing Gross National Happiness, Centre for Bhutan Studies, Thimphu, Bhutan, pp. 496-531.

Hofstede G. 1993. Cultural constraints in management theories. The Executive 7(1): 81-94.

James R. 2004. Exploring OD in Africa: a response to David Lewis. Nonprofit Management and Leadership 14(3): 313-324.

Kuensel Newspaper. 2008. Online www.kuenselonline.com accessed [10 October 2007; 15 March 2008].

Jaeger AM. 1986. Organization development and national culture: where's the fit? Academy of Management Review 11(1): 178-190.

Lau C, Ngo H. 2001. Organization development and firm performance: a comparison of multinational and local firms. Journal of International Business Studies 32(1): 95-114. 
Lokamitra D. 2004. The Centrality of Buddhism and Education in Developing Gross National Happiness, in Gross National Happiness and Development: Proceedings of the First International Conference on Operationalizing Gross National Happiness, Centre for Bhutan Studies, Thimphu, Bhutan, pp. 472-482.

Marshak RJ, Grant D. 2008. Organizational discourse and new organization development practices. British Journal of Management 19(s1): s7s19.

Mathou T. 2000. The politics of Bhutan. Journal Bhutan Studies 2(2): 252-262.

McAlpine K. 2007. Toolbox or transformation: is organizational development the key to unlocking the potential of civil society organizations in East Africa? Organization Development Journal 23(3): 111-115.

McCourt W, Ramgutty-Wong A. 2003. Limits to strategic HRM: the case of the Mauritian civil service. International Journal of Human Resource Management 14(4): 600-618.

O'Donnell M, Turner M. 2005. Exporting new public management: performance agreements in a Pacific microstate. The International Journal of Public Sector Management 18(6/7): 615-628.

Ozturk AO, Swiss JE. 2008. Implementing management tools in Turkish public hospitals: the impact of culture, politics and role status. Public Administration and Development 28(2): 138-148.

Pettigrew A, McKee L, Ferlie E. 1988. Understanding change in the NHS. Public Administration 66(3): $297-317$.

Planning Commission. 1999. Bhutan 2020: A Vision for Peace, Prosperity and Happiness, Royal Government of Bhutan: Bhutan.

Planning Commission. 2000. Bhutan National Human Development Report, Royal Government of Bhutan: Bhutan.

Porras JI, Silvers RC. 1991. Organization development. Annual Review of Psychology 42: 51-78.

Priesner S. 1999. Gross National Happiness-Bhutan's vision of Development and its Challenges, Gross National Happiness: A Set of Discussion Papers, Centre for Bhutan Studies, Thimphu, Bhutan.

Rainey HG. 2003. Understanding and Managing Public Organizations, (3rd edn). Jossey-Bass: San Francisco.

Rao TV, Vijayalakshmi M. 2000. Organization development in India. Organization Development Journal 18(1): 51-63.

Ritson N, O’Neill M. 2006. Strategic implementation: a comparison of three methodologies. Strategic Change 15(4): 187-196.

Royal Civil Service Commission (RCSC). website: www.rcsc.gov.bt accessed [9 October 2007].

Royal Civil Service Commission. 2006. Position Classification System Manual, Royal Government of Bhutan: Bhutan.

Royal Civil Service Commission. 2007. Organisational Development (OD) Exercises: Strategy Document, Royal Government of Bhutan: Bhutan.

Royal Government of Bhutan (RGoB). 2005a. Good Governance Plus: In Pursuit of Gross National Happiness, Royal Government of Bhutan: Bhutan.

Royal Government of Bhutan. 2005b. Position Classification System Policy Document, Royal Government of Bhutan: Bhutan.

Royal Government of Bhutan. 2006. Bhutan Civil Service Rules and Regulations, Royal Government of Bhutan: Bhutan.

Royal Government of Bhutan. 2007. Organisational Development (OD): Toward Excellence in the Civil Service, Royal Civil Service Commission: Bhutan.

Schumacher EF. 1966. Buddhist economics. In Asia: A Handbook, Wint G (ed.). Anthony Blond Ltd: London. Reprint available: http:// www.smallisbeautiful.org/buddhisteconomics.html

Sminia H, Nistelrooij AV. 2006. Strategic management and organization development: planned change in a public sector organization. Journal of Change Management 6(1): 99-113.

SNV. 2007. Strategy Paper 2007-2015 : Local Impact_Global Presence, Netherlands Development Organisation. The Hague.

Tashi KP. 2004. The role of Buddhism in achieving Gross National Happiness in Gross National Happiness and Development: Proceedings of the First International Conference on Operationalizing Gross National Happiness, Centre for Bhutan Studies, Thimphu: Bhutan, pp. 483-495.

Thinley JY. 1998. Values and Development: Gross National Happiness. Keynote address by the Bhutanese Chairman of Ministers to the Millennium Meeting for Asia and the Pacific, 30 October to 1 November, Seoul, Republic of Korea.

Thinley JY. 2005. What does Gross National Happiness (GNH) Mean? Keynote address by the Bhutanese Minister of Home and Cultural Affairs to the Second International Conference on Gross National Happiness, St Francis Xavier University, Antigonish, Canada, 20-24 June.

Tideman SG. 2001. Gross National Happiness: Towards Buddhist Economics. The New Economics Foundation: London.

Tompkins J. 2002. Strategic human resources management in government: unresolved issues. Public Personnel Management 31(1): 95-110.

United Nations Development Programme. 2006. Institutional Reform and Change Management: Managing Change in Public Sector Organisations, Capacity Development Group, Bureau for Development Policy, Conference paper \#5, United Nations: New York.

Ura K. 2004. The Bhutanese Development Story, Monograph \# 15, Centre for Bhutan Studies, Thimphu, Bhutan.

Waddell DM, Cummings TG, Worley CG. 2007. Organisation Development and Change: Asia Pacific (3rd edn). Thomson: South Melbourne.

Zupan N, Kase R. 2005. Strategic human resource management in European transition economics: building a conceptual model on the case of Slovenia. International Journal of Human Resource Management 16(6): 882-906. 